Clío América/ Vol. 13, No. 25 - 2019 / 298 - 307

DOI: http://dx.doi.org/10.21676/23897848.3414

\title{
EL TURISMO COMO CONTRIBUCIÓN AL CRECIMIENTO DEL PIB, PARA EL DESARROLLO DE LA ECONOMÍA DEL PAÍS
}

\section{TOURISM AS A CONTRIBUTION TO GDP GROWTH, FOR THE DEVELOPMENT OF THE COUNTRY'S ECONOMY}

\author{
Johana Milena Mogrovejo-Andrade ${ }^{1}(\mathbb{D})$, Sheyla Vanessa Herrera-Martínez ${ }^{2}$, Lissette Gabriela Maldonado- \\ Niño $^{3}$ (iD Nelson Emilio García-Torres ${ }^{4}$ (iD)
}

${ }^{1}$ Universidad Libre, Colombia. Email: johannam.mogrovejoa@unilibre.edu.co

${ }^{2}$ Universidad Francisco de Paula Santander, Colombia. Email: Sheylavanessahm@ufps.edu.co

${ }^{3}$ Universidad Francisco de Paula Santander, Colombia. Email: lissettegabrielamn@ufps.edu.co

${ }^{4}$ Universidad Francisco de Paula Santander, Colombia. Email: nelsonemiliogt@ ufps.edu.co

Para citar este artículo: Mogrovejo, A. J., Herrera, M. S., Maldonado, N. L., García, T. N. (2019). El turismo como contribución al crecimiento del PIB, para el desarrollo de la economía del país. Clío América, 13(25), 298-307. doi: http://dx.doi.org/10.21676/23897848.3414

Recibido: 08 marzo de 2019

Aceptado: 22 de mayo de 2019

Publicado en línea: mayo 24 de 2019

Palabras clave:

competitividad;

crecimiento

económico;

impacto

económico;

producto

interno bruto;

turismo.

JEL: R11.

\section{Keywords:}

Competitiven

ess; economic

growth;

economic

impact; gross

domestic

product;

tourism.

\section{RESUMEN}

Esta investigación parte del macroproyecto "apuestas de competitividad de la ruta agroturística del sector cafetero del municipio de Gramalote Norte de Santander" que está realizando la Universidad Francisco de Paula Santander con la Federación Nacional de Cafeteros, donde se pretende identificar la creciente participación del turismo en la economía colombiana y sea eje impulsador de la economía regional y nacional. Debido a las nuevas tendencias, los mercados han empezado a incursionar en nuevos modelos de negocios, donde la principal opción se centra en los diferentes tipos de turismo como un impulsador de la económica de los países, se propone identificar el aporte del sector turismo en la economía del país. Donde se desarrolla una investigación con un enfoque descriptivo, aplicada con diseño documental y revisión teórica. Los resultados obtenidos con esta investigación evidencian que el sector turismo en Colombia según reporte de los indicadores económicos se ha incrementado en un $150 \%$ y muestra una considerable participación en la economía colombiana. Como conclusión, el turismo es un motor económico y de igual manera se constituye un referente importante de ingresos para el país a partir de la diversificación en los destinos turísticos para la competitividad.

\section{ABSTRACT}

This research starts from the macro project "Competitiveness bets of the coffee sector agro-tourism route of the Gramalote Norte de Santander municipality". This project is being carried out by the Francisco de Paula Santander University with the National Federation of Coffee Growers. It is intended to identify the increasing participation of tourism in the Colombian economy and to be the driving force behind the regional and national economy. Markets have started to venture into new business models due to new trends, where the main option is focused on different tourism types, as a booster for countries' economy. Therefore, it is proposed to identify the contribution of the tourism sector in the national economy. It is developed an investigation with a descriptive approach, applied with documentary design and a theoretical revision. The results obtaine d show that, according to the report of the economic indicators, the tourism sector in Colombia has increased by $150 \%$, proving its considerable participation. In conclusion, tourism is an economic engine and a significant income reference for the count ry from diversification in tourist destinations for competitiveness. 


\section{INTRODUCCIÓN}

La creciente globalización de la economía permite ampliar constantemente las comunicaciones y obtener información sobre las nuevas actualizaciones tecnológicas. En esta dinámica, los países se preocupan por una mayor competitividad de sus economías a través de la creación de incentivos nacionales que agrupen tanto las instituciones gubernamentales como las empresas del sector privado y las personas de cada localidad. El PIB es un indicador que mide el crecimiento económico de un país. Es el más utilizado, ya que representa el valor de todos los bienes y servicios finales producidos durante un determinado periodo en un país. Estos valores son aportados por los diferentes sectores económicos, como el manufacturero, la agricultura, la construcción, la industria del turismo, entre otros. Hay varios sectores que aportan al crecimiento del PIB. En cuanto a la industria turística, esta ha representado, en los últimos años, una importante participación en el crecimiento económico de muchos países. Su evolución y desarrollo ha permitido a los países afrontar crisis, y los ha ayudado a mantener o mejorar su economía. Dicha evolución les permite a las naciones darse a conocer como nuevos destinos turísticos, y en consecuencia hacen que el turismo pase a convertirse en el eje principal del desarrollo económico. El surgimiento de nuevos destinos con características diferenciadoras, tanto de actividades como geográficamente, ha complementado el proceso de diversificación del turismo.

Las actividades realizadas en el turismo ayudan al impulso de las poblaciones. Cuanto más crezca el interés por un sitio turístico, mayor será el esfuerzo por mantener las en condiciones óptimas de los territorios y la economía. Esto permite abrir nuevos puestos de trabajo; al aumentar la categoría, mejoran los niveles de la población en educación y cultura. El desarrollo de este sector ha generado el incremento de incentivos para el desarrollo de las regiones en los diferentes niveles. Por otra parte, los beneficios se centran para otros sectores que tienen una relación indirecta con las actividades turísticas, como el sector de la construcción, la tecnología, las telecomunicaciones, el alimenticio, entre muchos otros, permitiendo, de esta manera, que todos los actores involucrados en el turismo sean parte del proceso desarrollador para la creación de una mayor diversificación en los destinos turísticos.

Según Agüera (como se citó en Villanueva, 2017), "la principal preocupación de esos nuevos destinos [...] la encontramos en intentar conseguir un turismo sostenible, alternativo al tradicional turismo de masas, que a la vez sea capaz de conseguir el desarrollo económico de esas zonas" (p. 36), respetando el medio ambiente. Esto lo demuestra el hecho de que los indicadores reflejen el impacto que tiene el turismo en la economía del país y su modo de generar empleo en las regiones.

Debido al potencial turístico de Colombia, desde hace varias décadas se viene creando la caracterización del turismo como sector alternativo para el incremento económico de la nación. En 1931 se creó el Centro de Turismo. Sin embargo, este sector no ha tenido la participación proyectada en la economía debido a la poca presencia de autoridades (Policía, Ejército Nacional, entre otros), por temas de seguridad, infraestructura en mal estado, percepción de país y poca confianza para ser elegido como lugar turístico. Con base en esta observación, en los últimos años el país ha evidenciado un cambio en el afianzamiento del turismo interno y el comienzo de la restructuración del turismo receptor, ya que en estos dos factores se han generado expectativas para el crecimiento económico del país.

\section{METODOLOGÍA}

Se realizó una investigación con un enfoque descriptivo. Se analizaron datos, características y otros aspectos importantes que sirvieron de base para identificar el comportamiento del turismo en la economía y el aporte del sector al PIB. De acuerdo con Hernández, Fernández y Baptista (2014), "se utiliza la recolección de datos para probar hipótesis con base en la medición numérica y el análisis estadístico, con el fin de establecer pautas de comportamiento y probar teorías" (p. 4).

Esta investigación está apoyada en la aplicación de un diseño documental, en el que se plasmaron los principales autores, los datos sobre la actualidad y la competitividad del turismo. También incluyó información recolectada de fuentes secundarias, con base en trabajos e investigaciones ya existentes. Así mismo, se tuvieron en cuenta datos de entidades como la Organización Mundial del Turismo (OMT), el Departamento Administrativo Nacional de Estadística (DANE), el Ministerio de Comercio, Industria y Turismo (MinCIT), además de datos e información de la Federación Nacional de Cafeteros (FNC), la Corporación Mixta, el Clúster Mánager de Turismo, la Comisión Regional de Competitividad de Norte de Santander e Invest in Cúcuta, entre otras entidades gubernamentales y no gubernamentales.

\section{RESULTADOS}

Para empezar, es importante tener claridad sobre el significado del turismo, el PIB y la relación de estos con el crecimiento económico. Según la OMT (2008), el turismo es el movimiento sociocultural y económico articulado con 
el desplazamiento de los seres humanos a destinos que se localizan en lugares diferentes a donde residen, ya sea por motivos de negocios, personales o por cualquier otro factor relacionado con las personas. En otras palabras, el turismo "es una de las pocas actividades humanas capaz de dar lugar a campos de investigación tan variados como la economía, la ecología, la psicología, la sociología, las ciencias políticas y las ciencias empresariales" (Requena y Muñoz, 2006, p. 121).

Cabe señalar que el PIB es el indicador que registra la producción de bienes y servicios de una economía en un periodo determinado. El DANE (2018) lo define como la consecuencia final de un periodo determinado de la actividad productiva, teniendo en cuenta los elementos productivos de los residentes. Este se utiliza para conocer el crecimiento de la economía en relación con los años anteriores, y de esta manera tomar decisiones que ayuden a su crecimiento. Para obtener el cálculo del PIB se deben tener en cuenta todas las producciones que se realicen en las fronteras geográficas de la nación, bien sea por individuos o compañías locales o del extranjero.

Es de vital importancia calcular el PIB para cada sector que influye en la economía, es decir, en los siguientes sectores: "Agropecuario, Minería, Industria Manufacturera, Suministro de electricidad, gas y agua, Construcción, Comercio, transporte y hoteles, Información y comunicaciones, Actividades financieras, Actividades inmobiliarias, Actividades profesionales, Administración pública, Arte, entretenimiento y recreación e Impuestos" (Ministerio de Hacienda y Crédito Público, 2019, p. 48). Según el informe de la Asociación Colombiana de Agencias de Viajes y Turismo (Voces 365, 28 de agosto de 2017):

En Colombia el turismo representa el 2,8\% del PIB, pero de acuerdo con estimaciones de la WTTC, el aporte indirecto es del 5,8\%, lo que evidencia lo importante de esta rama económica, puesto que promueve la actividad comercial en las ciudades impactando no solo a los prestadores de servicios turísticos sino a toda la economía local.

De acuerdo con los datos del Centro de Información Turística de Colombia, con base en el DANE, la cuenta de hoteles y restaurantes ha tenido un crecimiento del $24 \%$ en los últimos seis años, $6,9 \%$ por encima del promedio nacional que se registró en $17 \%$, según los datos a cierre de 2017. También es importante resaltar que, según datos del Banco de la República para el mismo periodo, el ingreso de divisas al país por concepto de turismo creció $5,4 \%$ frente al 2016.
Por consiguiente, el turismo es uno de los sectores que durante los últimos años ha sido importante en el crecimiento económico, debido a que esta actividad se ha transformado en un factor benéfico para las exportaciones del mundo. Está generando incremento en los ingresos y fuentes de empleo, tanto directas como indirectas. Para muchas naciones en vía de desarrollo, es un método para ser competitivos e impulsar el sector de los servicios. De igual manera, este sector ha permitido crear un impacto multiplicador para que las naciones desarrollen su infraestructura, factores que son indispensables para conseguir la posición deseada en la competitividad de los mercados internacionales. Por consiguiente, el crecimiento del sector ha beneficiado con mejores ingresos al Gobierno por medio del cobro de impuestos al sector.

Según reporte del DANE (2018), el PIB para el primer trimestre de 2018 de las actividades económicas del país refleja un crecimiento del 2,2\%, influido principalmente por actividades financieras y de seguros, de administración pública y defensa, profesionales, científicas y técnicas, artísticas, de entretenimiento y recreación, de comercio al por mayor y al por menor, de información y comunicaciones e inmobiliarias, cuyos crecimientos superan el promedio. En otras actividades, como valor agregado, construcción, minas y canteras, industria manufacturera, suministro de electricidad, gas, vapor y aire y agricultura, ganadería, caza, silvicultura y pesca, sus crecimientos presentan un desempeño por debajo del promedio.

Las actividades económicas turísticas están constituidas por diversas áreas. Están impulsadas por sitios como jardines botánicos, zoológicos, parques naturales, parques de atracciones, parques temáticos, actividades deportivas, actividades de museos y lugares históricos y otras diferentes actividades de turismo. Estas actividades tuvieron un crecimiento para el primer periodo trimestral de 2018, pues según el boletín técnico del DANE (2018) las actividades turísticas crecieron 3,4\%. Este comportamiento se explica con el incremento del $4,2 \%$ en las actividades artísticas y el incremento del 1,2\% en las de los hogares individuales en calidad de empleadores. Ello refleja la importancia del turismo como motor de crecimiento económico.

En este orden, para el segundo trimestre de 2018, de acuerdo con el DANE (2018), se señala que el PIB creció originalmente $2,8 \%$, comparado con el mismo periodo del 2017. Este incremento en el PIB se debe a que lo sectores de las actividades profesionales, científicas y técnicas, servicios administrativos y de apoyo; la agricultura, ganadería, caza, silvicultura y pesca, y, por último, el sector 
de la construcción crecieron $6,6, \quad 5,9$ y 7,6\% respectivamente, teniendo en cuenta que el sector construcciones creció de forma negativa.

Debe señalarse que la mayor tasa de crecimiento anual del PIB en el tercer trimestre de 2018 la logró la administración pública, defensa, educación y salud $(4,5 \%)$, seguido de información y comunicación $(3,7 \%)$, industria manufacturera $(2,9 \%)$, valor agregado $(2,6 \%)$, actividad inmobiliaria $(2,1 \%)$, construcción $(1,8 \%)$ y agricultura, ganadería, caza, silvicultura y pesca $(0,1 \%)$. Estos resultados determinan un crecimiento ponderado del PIB total a una tasa del 2,7\% respecto del año anterior. Cabe señalar que la mayor tasa de crecimiento la presenta el sector de la construcción $(6,5 \%)$ y la actividad de menor crecimiento fue la agricultura, ganadería, caza, silvicultura y pesca, con una tasa negativa de crecimiento del $1,6 \%$. En este grupo, el PIB ponderado fue del $0,2 \%$ de crecimiento. En este orden de ideas, con relación a la tasa de crecimiento, el mayor desempeño se presentó en la administración pública, defensa, educación y salud, con una tasa del 5,2\%. El menor crecimiento lo muestra la construcción, con una tasa negativa del 2,5\%. El PIB ponderado señala un crecimiento con una tasa del $2,5 \%$.

En el último trimestre de 2018 se observa, en la figura 1, que la mayor tasa de crecimiento anual del PIB en el cuarto trimestre la logró la construcción (12,2\%), y la siguen, en su orden, la administración pública, defensa, educación y salud $(4,3 \%)$, el valor agregado $(3,4 \%)$, la actividad inmobiliaria $(1,9 \%)$, la agricultura, ganadería, caza, silvicultura y pesca $(0,8 \%)$ y la información y comunicación $(0,5 \%)$. La industria manufacturera disminuyó $0,3 \%$. Estos resultados determinan un crecimiento ponderado del PIB total a una tasa del 3,3\% respecto del año anterior.

Cabe señalar que en materia de tasa de crecimiento serie corregida de efecto estacional y calendario, la mayor tasa de crecimiento la presenta el sector de la construcción, con $17,4 \%$, y la actividad de menor crecimiento fue la agricultura, ganadería, caza, silvicultura y pesca, con una tasa negativa de crecimiento del $0,9 \%$. En este grupo el PIB ponderado fue del 1,8\% de crecimiento.

Figura 1. Crecimiento del PIB para el Cuarto Trimestre de 2018

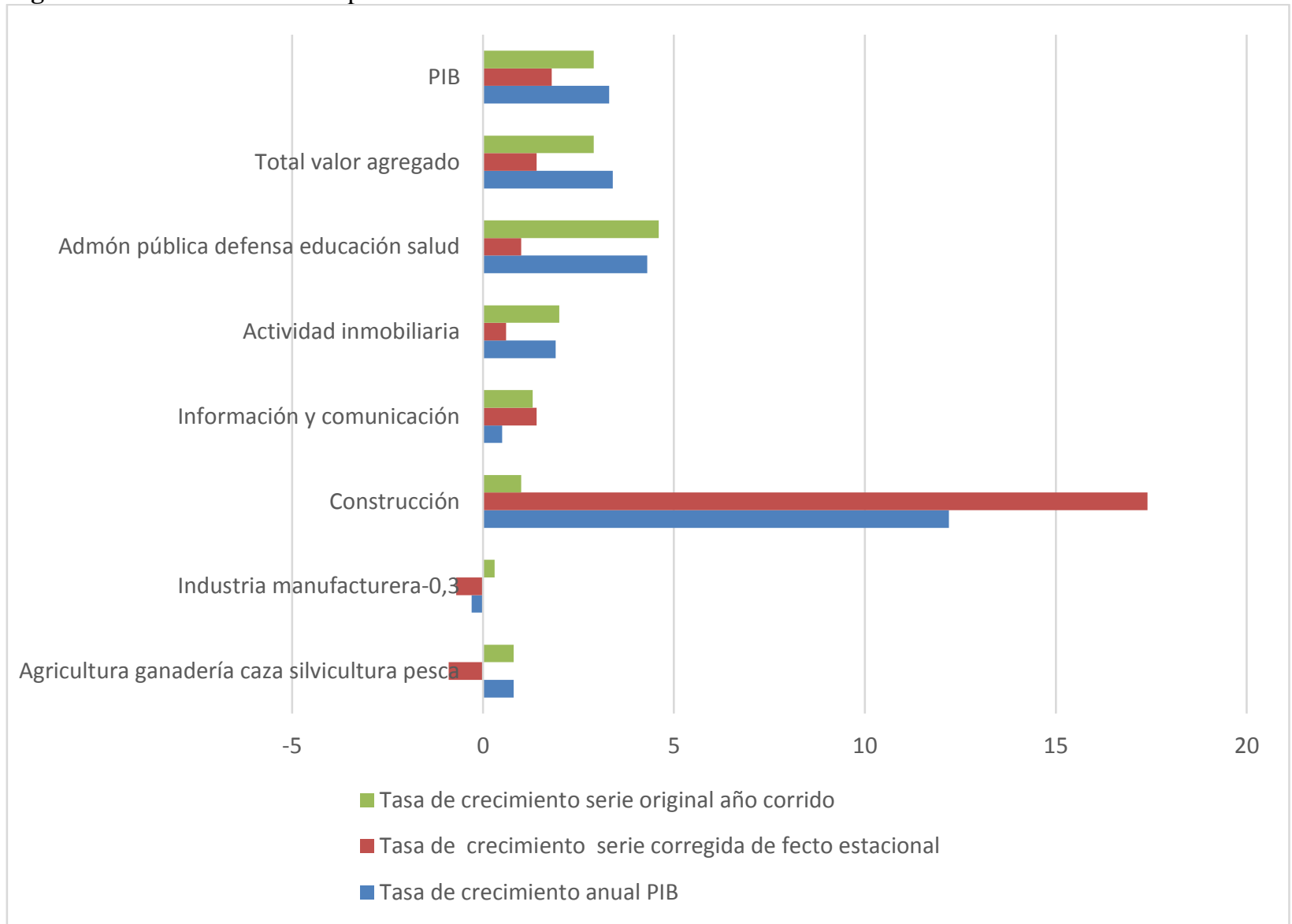

Fuente: Boletín técnico, DANE (2018). 
En este orden de ideas, con relación a la tasa de crecimiento serie original año corrido, el mayor desempeño se presentó en la administración pública, defensa, educación y salud, con una tasa del 4,6\%, y el menor crecimiento lo muestra la industria manufacturera, con una tasa del $0,3 \%$. El PIB ponderado señala un crecimiento a una tasa del $2,9 \%$.

Las actividades turísticas han presentado un aumento representativo en los últimos años, pasando de representar el $2 \%$ del PIB en 1999 a casi el $3 \%$ del PIB en 2017 (Clavijo, 2018). Si bien se puede observar las actividades turísticas tienen una evolución positiva en el PIB, en los últimos seis años la industria del turismo creció $24 \%$ según las publicaciones de la Revista Portafolio (2018), a pesar de que no representa ni el $5 \%$ del PIB del país, se ve al turismo como un importante multiplicador económico de la nación.

Teniendo en cuenta las publicaciones mensuales sobre el sector turismo del MinCIT, Colombia se encuentra entre los cinco países con mayor ingreso de extranjeros en América Latina, lo que genera el $0,31 \%$ de la población migratoria en el mundo. Este posicionamiento se ha logrado con el incremento de turistas extranjeros en Colombia en los últimos años, y que en agosto de 2018, según el informe de MinCIT en el ingreso de extranjeros al país, incrementó el $18,3 \%$, y en lo que va del año su aumento es del 35,5\%. "Los principales países orígenes en lo corrido del año son Estados Unidos, Venezuela, y Argentina, fueron los países con mayor contribución a las llegadas de extranjeros, participando con 15,8\%,33,9\% y 5,5\%, respectivamente" (MinCIT, 2018).

Los departamentos con mayor crecimiento en lo corrido del año son: Nariño, con 238,7\%; Norte de Santander, con $77,2 \%$; La Guajira, con 65,3\%, y Antioquia, con 20,7\%. Los departamentos con menor crecimiento son: San Andrés y Providencia, con $-2,7 \%$, y Valle del Cauca, con $-2,0 \%$ (MinCIT, 2018). Pero los turistas extranjeros no representan el único indicador que aumentó en el país. El turismo interno, que consiste en los viajes que realizan los mismos residentes dentro del país de origen, aumentó. Por tal motivo, también se toma como turismo interno esos viajes realizados por las personas fuera del lugar donde residen, ya sea por motivos laborales o por simple ocio. Para el periodo enero-agosto transitaron 28.442.370 vehículos. Los departamentos más representativos fueron Santander (35,9\%), Boyacá (11,1\%) y Antioquia 5,3\%. En total, se registró un crecimiento del $106,9 \%$ en el tránsito de automóviles (MinCIT, 2018).

Desde 2010 las estadísticas han aumentado de manera favorable debido a las campañas publicitarias y a la participación en conjunto de los gremios para mejorar la imagen de la nación. En Colombia, el turismo representa el 2,8\% del PIB, pero según estimaciones del Consejo Mundial de Viajes y Turismo (WTTC), el aporte indirecto es del 5,8\%, lo que presentó un significativo aumento económico en referencia al turismo, ya que impulsa la actividad comercial en las localidades. Esto tiene efectos positivos tanto para las entidades que prestan servicios turísticos como para la economía en general.

Cabe considerar que la industria del turismo y sus datos prueban que el sector tiene una tendencia a impulsar la economía, teniendo en cuenta que

En la actualidad se ha registrado un aumento en la llegada de visitantes extranjeros al país de $150 \%$ en los últimos ocho años. Es decir, el número de turistas en el país pasaron de 2,6 millones en 2010 a 6,5 millones hasta el momento (Dinero, 13 de julio de 2018, p. 01).

En este orden de ideas, de acuerdo con la Balanza de Pagos del Banco de la República, "en las últimas dos décadas el segmento de Comercio, Restaurantes y Hoteles generó inversiones por US\$14,55 millones" (Procolombia, 2018, p. 1). Además, en materia de divisas, el sector turístico alcanzó "cifras récord durante 2017, llegando a US\$5,787 millones, lo que ha convertido al sector en el segundo sector generador de divisas en el país" (p. 1). Según el MinCIT, para 2020 "el aporte en el Producto Interno Bruto por parte del sector será de $\$ 37,3$ billones. Una cifra que, de lograrse, sería la más alta de los últimos 15 años [...] en la última década, el aporte al PIB del turismo se ha mantenido en una senda de crecimiento entre el 3,5\% y 3,8\%" (Vanguardia, 2020, p. 1). Esto evidencia cómo la Balanza de Pagos se impacta por el turismo internacional y estimula el crecimiento económico en el país mediante recursos provenientes del extranjero.

Las actividades turísticas generan un gran impacto en la economía, en el ambiente natural donde se desarrollan, en la infraestructura en la que se lleva acabo, en los habitantes de las localidades que son visitadas y, por consiguiente, en los visitantes, a quienes debe generarles experiencias agradables y satisfactorias para volver al sitio turístico. Teniendo en cuenta los diferentes factores que crean un efecto, la diversificación y las variaciones de los elementos que influyen en la producción, y que son indispensables para producir los bienes y servicios que a fin de cuentas son adquiridos por las personas que visitan el destino turístico, además de la interacción de las instituciones involucradas o afectadas por el sector, es indispensable ver al turismo como estrategia global de desarrollo, para el trabajo y la 
evaluación de este.

Aparte de las posibles variantes que tenga el turismo, la calidad de la actividad se enfoca en dos factores fundamentales. Uno consiste en la acción y reactivación económica que produce en la región donde se lleva acabo. De este modo, la mayoría de las naciones y regiones del mundo determinan que las actividades turísticas como generadores económicos se diversifican y aumentan los empleos, la inversión en la infraestructura, los avances de innovación en los sitios gastronómicos y hoteleros y el aumento de los diferentes medios de transportes. De igual manera, se conocen zonas en el mundo que son clasificadas como importantes y competitivas en turismo, y otras no tanto. Esto se debe mayormente al interés de cada nación por mostrarse al mundo como un potencial destino turístico diferenciado de otros.

De acuerdo con la OMT, en estos momentos el crecimiento de este tipo de actividades económicas se compara con las exportaciones de varios sectores importantes en la económica global. Por tal motivo, las actividades turísticas se posicionan como factor fundamental del comercio y se comprenden como el ítem que mayor aporta a la economía para una gran cantidad de países en desarrollo. Las actividades turísticas representan un factor importante de ingresos de dinero del extranjero que ayudan a la estabilidad macroeconómica. En esta dinámica, se debe tener en cuenta que para muchos países en desarrollo los habitantes laboran en actividades turísticas en un país diferente a su nación natal y producen un aumento en el movimiento de divisas (OMT, 2008).

Conforme a las reflexiones expuestas, el turismo se presenta como una fuente distintiva para el impulso del crecimiento y la estabilidad económica en el país; es un movimiento económico y cultural significativo que puede identificar una nación. El valor de este negocio reside en que el turismo genera una reactivación económica dependiendo como se realice la actividad turística.

\section{DISCUSIÓN}

Se ha evidenciado un crecimiento de la participación de las actividades turística, siendo el mismo motor de la economía donde se realizan las actividades. De acuerdo con los autores Londoño y Vargas (2016) "el desarrollo del turismo nacional e internacional puede aportar a la vida de la nación, a través de una oferta bien concebida y de calidad, que proteja y respete el patrimonio cultural, el medioambiente natural, social y humano" (Londoño G.M., et.al. 2016, p.40). En Colombia se tiene como estrategia fortalecer el turismo y algunas regiones cuentan con fiestas que son parte de la cultura que promueven el turismo y la economía.

Dentro de este marco, es evidente la importancia de comprender las teorías del turismo y su incidencia en la dinámica social, económica y ambiental de las naciones y regiones en donde las autoridades estatales ejercen un rol significativo. En este contexto, Plaza (2013) establece que el turismo rural es un gran potencial debido a que se ha incrementado el interés por conocer las tradiciones y los entornos de estas áreas geográficas, apuntándole de esta manera a la sustentabilidad en el desarrollo del territorio, lo que involucra a la población local. Con base en esto, Garcés, Sarmiento y Paneca (2018) determinan que a partir de las teorías se fijan los factores para la competitividad turística que se deben incorporar como estrategia basada en la innovación, el capital humano, la realización de alianzas estratégicas de la mano de la planeación y el mejoramiento continuo. Así mismo, Bravo y Rincón (2013) también analizan la competitividad, y concluyen que se deben realizar inventarios turísticos, articulación con las entidades de apoyo, ya sean gubernamentales o privadas, y estudios de mercadeo.

Por otro lado, Laguado, García y Herrera (2016) establecen que se deben crear estrategias de mercadeo con el fin de enfrentar los cambios del mercado y la competencia, y así lograr posicionarse en la mente de los consumidores. Por lo anterior, González (2005) indica que, desde las estructuras de mercadeo, es necesario articularse con la teoría económica para solucionar los problemas a corto y a largo plazo, teniendo como base el capital, el trabajo y la tierra. Tales estrategias permitirán que el turismo colombiano se vuelva atractivo para los habitantes del país y del extranjero, y se convierta en un servicio de consumo importante que pueda incentivar el crecimiento.

En la revisión de datos se hallaron varios aspectos, como el incremento de los turistas, la creación de nuevos centros turísticos y el crecimiento económico. Estos factores van de acuerdo con lo que plantean Riveros y Blanco (2003), quienes señalaron que el turismo rural probablemente sea una de las actividades de la especie humana donde interrelaciona un sinfín de variables, pues se presenta como un actor dinamizador que genera trabajo, ingresos y diversifica el mercado de servicios. Este modelo de turismo se relaciona también con las actividades artísticas, la recreación, la valorización y la preservación de herencias culturales. Por otra parte, se referencia a la coordinación y gestión de recursos naturales y al uso responsable de los ecosistemas dentro de este tipo de turismo.

En el análisis del sector turismo es importante conocer 
cuánto resalta en la economía de una nación, para poder examinar la relevancia del turismo en la generación de dineros inteligentes, diversificación de productos, aportaciones al PIB, generador de empleo, con la finalidad de aportar información útil que sea relevante para la creación de estrategias que contribuyan al crecimiento positivo que ha presentado el sector turístico en los recientes años. Así mismo los autores, Rodríguez, Feder y Fratucci (2015) señala que "analizado como causante de transformaciones negativas y positivas para la sociedad y su medio, el turismo pasa a ser observado como un fenómeno socio-espacial complejo y contemporáneo" (Rodríguez S., et.al., 2015, p.118), es por ello que presenta dificultad para medir el impacto económico.

A sabiendas de que el turismo lleva de fondo una tendencia natural de los seres humanos a trasladarse de un lugar a otro, se puede constituir en un movimiento socioeconómico que interviene en el desarrollo cultural y en el enriquecimiento de las poblaciones. El turismo es una de las actividades económicas que impacta en la cultura; presenta diferentes variantes, lo cual tiene efecto en diferentes grupos de segmentos de mercado, genera empleo, mejora la infraestructura de hoteles, restaurantes y fortalece la infraestructura regional y nacional (Bembibre, 29 de mayo de 2011).

Un estudio revelado por la revista Pasos, de la Universidad Laguna de España, realizado por Brida, Monterubbianesi y Zapata (2011), analizó los impactos del turismo y sus efectos en el crecimiento económico que se relaciona directamente con el ingreso de divisas, el aumento del empleo, la innovación con la tecnología, la generación de nuevo negocios y la articulación con sectores afines. De este modo se han ido desplazando los sectores tradicionales.

Por otro lado, Cárdenas (2001) establece que es relevante en el sistema turístico tanto los bienes como los servicios, ya que dependen mutuamente. Según Gurría (2004), la demanda y la oferta deben regularse para tener un sistema armonioso. Por su parte, Resico (2010) se enfoca en la economía social como respuesta para solucionar problemas a inversionistas, ahorradores, consumidores para la toma de decisiones a mediano y largo plazo.

El turismo competitivo será el que avale a largo plazo los nuevos atractivos turísticos. Por lo tanto, la implementación y los nuevos destinos turísticos en las diferentes regiones del país han sido un factor clave en el crecimiento del sector, debido a que las nuevas tendencias de turismo resaltan que los viajeros están optando por destino diferentes al tradicional de playa y sol. De tal modo, es evidente que la diversidad es un factor clave en la competitividad del turismo.

\section{CONCLUSIÓN}

Después del análisis se percibe que el turismo es una variante muy importante para el impulso económico. Es un generador de beneficios como el incremento de divisas a partir de las exportaciones de productos turísticos, la creación de empleo, el incremento de la participación monetaria local y el respectivo crecimiento de la efectividad local, generado por la competitividad de otros destinos. Por otra parte, investigaciones resaltan el impacto indirecto que produce el factor turístico en las actividades económicas; esto debido a unos encadenamientos de sucesos que permiten una relación con los demás sectores que tienen una tradición más fuerte en la economía y el potencial que tiene para impulsar indirectamente otros sectores.

El turismo genera crecimiento económico, lo que da vía a que se desarrollen otras oportunidades de mejoramiento en las poblaciones que promueven el turismo. De este modo se satisfacen las necesidades básicas y se reduce la pobreza, a través de la educación, el mejoramiento de las unidades básicas de salud y la inversión en la infraestructura de la localidad.

No obstante, el turismo también puede impactar de manera desfavorable en la estabilidad de la población y de los países donde se realizan sus actividades, caracterizados por el consumo de bienes y servicios que no son de exportación. Estas compras realizadas por los visitantes extranjeros influyen directamente en el incremento del valor precio de los bienes, lo que perturba el consumo de la región afectada por el alza de sus precios y, en consecuencia, altera la tranquilidad de la zona. Con base en esto, se propone que, ante el crecimiento del turismo, los productos no exportables de este sector requieran un mayor número de trabajadores, teniendo en cuenta, sin embargo, que esto puede afectar otros sectores.

Es cierto que el turismo afecta la economía de manera positiva, pero debe superar algunas situaciones negativas. Dentro de los aspectos negativos resaltan los problemas de inseguridad, la ineficiencia en la infraestructura vial y la poca accesibilidad e inversión, hechos que impiden realizar y desarrollar las actividades turísticas.

También hay factores que requieren la participación de entidades como Procolombia, las gobernaciones de cada departamento, el acompañamiento de las autoridades, la Cámara de Comercio, los gremios y la Secretaría de 
Desarrollo Económico, que a través de un trabajo conjunto permiten mejorar todos los aspectos que son en este momento barreras que impiden el desarrollo de las actividades turísticas. Por otra parte, el nivel educativo y cultural de las poblaciones que son destinos turísticos influye de manera positiva en la competitividad del sector, por lo cual se considera importante ofrecer los servicios de calidad, y de este modo se impulsa la capacitación del talento humano.

En el país hay regiones que están más preparadas para recibir el turismo que otras. Sus características, su infraestructura y sus fiestas culturales han logrado un gran desarrollo en este sector y son líderes para organizar diferentes tipos de turismo. Esto nos permite concluir que el país tiene fortalezas para promover diversos tipos de turismo, pero requiere más preparación y apoyo gubernamental en algunas regiones para que se fortalezcan.

\section{Declaración sobre conflictos de interés}

Este articulo surge de un proyecto en alianza con los docentes de la Universidad Libre, seccional Cúcuta, y de la Universidad Francisco de Paula Santander, pertenecientes a los grupos de investigación GIGSD, GILOCNI y GIDSE. En estos se llevó a cabo un proyecto de turismo, y de este surge el presente artículo. Sus resultados son independientes con respecto a las instituciones financiadoras y de apoyo, y durante la ejecución del trabajo o la redacción del manuscrito no han incidido intereses o valores distintos a los que usualmente tiene la investigación.

\section{REFERENCIAS BIBLIOGRÁFICAS}

Bembibre, C. (29 de mayo de 2011). Importancia del turismo [Mensaje en un blog].

https://www.importancia.org/turismo.php

Bravo, A. y Rincón, D. (2013). Estudio de competitividad en el sector turismo en Colombia (tesis de pregrado). Universidad del Rosario, Bogotá, Colombia.

https://repository.urosario.edu.co/bitstream/ handle/10336/4269/1020746197- 2013.pdf?sequence $=5$

Brida, J., Monterubbianesi, P. y Zapata, S. (2011). Impactos del turismo sobre el crecimiento económico y el desarrollo. El caso de los principales destinos turísticos de Colombia. Pasos: Revista de Turismo y Patrimonio Cultural, 9(2), 291-303.

Clavijo, S. (5 de marzo de 2018). PIB-real 2017 y perspectivas 2018. Recuperado de: https://www.larepublica.co/analisis/sergi o-clavijo-500041/pib-real-2017-yperspectivas-2018-2605600

Cárdenas, F. (2001). Comercialización del turismo. Ciudad de México: Editorial Trillas.

Departamento Administrativo Nacional de Estadística - DANE. (2018). Producto Interno Bruto (PIB). Históricos, para la economía colombiana (Boletín técnico $\begin{array}{lll}\text { trimestre } & \text { I- }\end{array}$ https://www.dane.gov.co/index.php/estadisti cas-por-tema/cuentas-nacionales/cuentasnacionales-trimestrales/historicos-productointerno-bruto-pib

Dinero. (13 de julio de 2018). Turismo: la prometedora industria que no contamina.

https://www.dinero.com/pais/articulo/balanc e-del-sector-turismo-en-colombia- 
Johana Milena Mogrovejo-Andrade, Sheyla Vanessa Herrera-Martínez, Lissette Gabriela Maldonado-Niño, Nelson Emilio García-Torres

$2018 / 260070$.

Garcés, Y., Sarmiento, Y. y Paneca, Y. (2018).

La competitividad turística: su medición y factores determinantes. Revista

Caribeña de Ciencias Sociales, 1(1). https://www.eumed.net/rev/caribe/2018/06/ competitividad-turistica.html

García, L. M. y Vargas, T. L. (2016). Visión estratégica del turismo en el paisaje cultural cafetero. https://www.ugc.edu.co/sede/armenia/files/e ditorial/vision_estrategica_de_turismo_pcc. pdf

González, H. (2005). Economía y empresa. Semestre Económico, 8(15), 117-135. https://www.redalyc.org/pdf/1650/1650136 59007.pdf

Gurría, M. (2004). Introducción al turismo. Ciudad de México: Editorial Trillas. Hernández, R., Fernández, C. y Baptista, P. (2014). Metodología de la investigación. Ciudad de México: McGraw-Hill. https://periodicooficial.jalisco.gob.mx/sites/ periodicooficial.jalisco.gob.mx/files/metodo $\underline{\text { logia_de_la_investigacion_- }}$ _roberto_hernandez_sampieri.pdf

Laguado A., García, P. A. y Herrera, M. S. V. (2017). Las tecnologías de información y comunicación y

la gestión empresarial. En Estudio del posicionamiento de marcas (top of mind - 2016) Cúcuta,

Colombia.
Londoño, G. M. L. y Vargas, T. L. C. (2016). Visión estratégica del turismo en el paisaje cultural cafetero. Recuperado de https://www.ugc.edu.co/sede/armenia/files/e ditorial/vision estrategica de turismo pcc. pdf

Ministerio de comercio, industria y turismo MINCIT. (2018). Boletín IV trimestre turismo. Recuperado de: http://www.mincit.gov.co/minturismo/eventos$\mathrm{y}$-publicaciones/boletin-informativo-del-sectorturismo.Ministerio de Hacienda y Crédito Público - MinHacienda. (2019). Marco Fiscal de mediano plazo. https://www.minhacienda.gov.co/webcenter/ShowP roperty?nodeId=\%2FConexionContent $\% 2$ FWCC_C LUSTER-

$\underline{111638 \% 2 F \% 2 F i d c P r i m a r y F i l e \& r e v i s i o n=l a t e s t r e l e}$ $\underline{\text { ased }}$

Organización Mundial del Turismo. (2008). Entender el turismo: glosario básico. https://www.unwto.org/es/glosarioterminos-turisticos

Plaza, D. (2013). Turismo rural como actividad dinamizadora del desarrollo local en la comuna de Curicó (tesis de pregrado). http://repositorio.uchile.cl/bitstream/handle/ 2250/113793/plaza_d.pdf?sequence $=1$

Portafolio. (15 de febrero de 2018). PIB 2017, mejor de lo esperado y señales positivas para el 2018. Recuperado de https://www.portafolio.co/economia/pib2017-mejor-de-lo-esperado-y-senalespositivas-para-el-2018-514321 
EL TURISMO COMO CONTRIBUCIÓN AL CRECIMIENTO DEL PIB, PARA EL DESARROLLO DE LA ECONOMÍA DEL PAÍS

Procolombia. (2018). Inversión en el sector Infraestructura de Hotelería y Turismo en Colombia. https://www.inviertaencolombia.com.co/sec tores/servicios/infraestructura-hotelera-yturismo.html

Requena, K. y Muñoz, J. (2006). El turismo e internet, factores de desarrollo en países subdesarrollados. Caso: Venezuela. Actualidad Contable Faces, 9(12), 118131.

https://www.redalyc.org/pdf/257/25701212. pdf

Resico, M. (2010). Introducción a la economía social de mercado. Buenos Aires: Konrad Adenauer Stiftung. Recuperado de

https://www.kas.de/c/document_library/get_ file?uuid=22412104-f255-886e-178f-

$\underline{8 b 32 b f 5 b c e 06 \& \text { group Id }=252038}$

Riveros, H. y Blanco, M. (2003). El agroturismo, una alternativa para revalorizar la agroindustria rural como mecanismo de desarrollo local. Lima: Prodar.

http://fediap.com.ar/administracion/pdfs/Ag roturismo\%20-

\%20Una\%20alternativa\%20para\%20revalor
izar\%201a\%20Agroindustria\%20Rural\%20( Hernando\%20Riveros).pdf

Rodríguez, M. S., Feder, M. V. y Fratucci, A. (2015). Impactos percibidos del turismo: un estudio comparativo con residentes y trabajadores del sector en Río de Janeiro-Brasil. Estudios y Perspectivas en Turismo, 24(1), 115-134. https://www.redalyc.org/pdf/1807/1807328 64007.pdf

Vanguardia. (2020). Turismo hará importante aporte en el PIB del país. https://www.vanguardia.com/economia/naci onal/turismo-hara-importante-aporte-en-elpib-del-pais-XM1860653

Villanueva, J. (2017). El turismo como motor de crecimiento económico sostenible; el caso especial del turismo rural (tesis doctoral).

https://ruidera.uclm.es/xmlui/bitstream/hand le/10578/16465/TESIS\%20Villanueva\%20

$\% \mathrm{C} 3 \% 811$ varo.pdf?sequence $=1$

Voces365. (28 de agosto de 2017). El turismo representa el 2,8\% del PIB, y será el principal motor de la economía del país: ANATO. https://voces365.com/turismorepresenta-28-del-pib-sera-principal-motorla-economia-del-pais-anato/ 